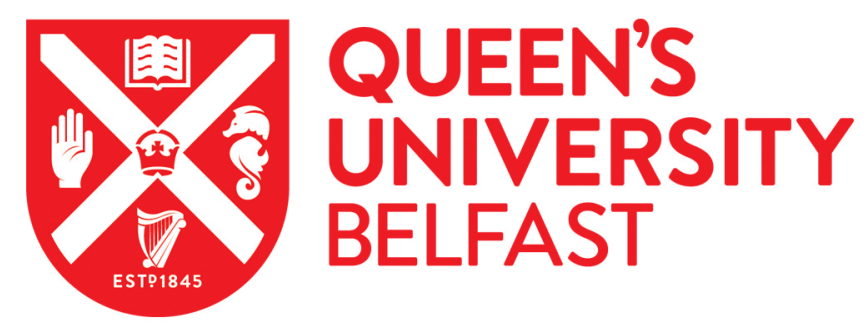

\title{
Development and evaluation of a technology-enhanced, enquiry- based learning program on managing neonatal extravasation injury: a pre-test/post-test mixed-methods study
}

Chau, J. P. C., Lo, S. H. S., Chan, K. M., Chan, M. Y., Lee, V. W. Y., Lam, S. K. Y., Choi, K. C., \& Thompson , D. R. (2021). Development and evaluation of a technology-enhanced, enquiry-based learning program on managing neonatal extravasation injury: a pre-test/post-test mixed-methods study. Nurse Education Today, 97, [104672]. https://doi.org/10.1016/j.nedt.2020.104672

Published in:

Nurse Education Today

Document Version:

Peer reviewed version

Queen's University Belfast - Research Portal:

Link to publication record in Queen's University Belfast Research Portal

\author{
Publisher rights \\ (C) 2020 Elsevier Ltd. \\ This manuscript version is made available under the CC-BY-NC-ND 4.0 license http://creativecommons.org/licenses/by-nc-nd/4.0/,which \\ permits distribution and reproduction for non-commercial purposes, provided the author and source are cited.
}

\section{General rights}

Copyright for the publications made accessible via the Queen's University Belfast Research Portal is retained by the author(s) and / or other copyright owners and it is a condition of accessing these publications that users recognise and abide by the legal requirements associated with these rights.

\section{Take down policy}

The Research Portal is Queen's institutional repository that provides access to Queen's research output. Every effort has been made to ensure that content in the Research Portal does not infringe any person's rights, or applicable UK laws. If you discover content in the

Research Portal that you believe breaches copyright or violates any law, please contact openaccess@qub.ac.uk. 
DEVELOPMENT AND EVALUATION OF A TECHNOLOGY-ENHANCED, ENQUIRYBASED LEARNING PROGRAM ON MANAGING NEONATAL EXTRAVASATION INJURY: A PRE-TEST/POST-TEST MIXED-METHODS STUDY

Janita P. C. Chau ${ }^{1}$, Suzanne H. S. Lo ${ }^{1 *}$, Kam Ming Chan ${ }^{2}$, Man Yi Chan ${ }^{3}$, Vivian, W. Y. Lee ${ }^{4}$, Simon K. Y. Lam ${ }^{1}$, Kai Chow Choi ${ }^{1,}$ David R Thompson ${ }^{5}$

*Correspondence: suzannelo@cuhk.edu.hk Tel: (852) 39434485

${ }^{1}$ The Nethersole School of Nursing, Room 826, 8/F, Esther Lee Building, Chung Chi College, The Chinese University of Hong Kong, Shatin, N. T., Hong Kong

\section{Authors' Details:}

${ }^{1}$ The Nethersole School of Nursing, Faculty of Medicine, The Chinese University of Hong Kong, Hong Kong. ${ }^{2}$ Department of Paediatrics and Adolescent Medicine, United Christian Hospital, Hospital Authority, Hong Kong. ${ }^{3}$ Department of Paediatrics and Adolescent Medicine, Princess Margaret Hospital, Hospital Authority, Hong Kong. ${ }^{4}$ Centre for Learning Enhancement And Research, The Chinese University of Hong Kong, Hong Kong. ${ }^{5}$ School of Nursing and Midwifery, Queen's University Belfast, Belfast, United Kingdom

Janita Pak Chun CHAU, PhD, Professor, The Nethersole School of Nursing, Faculty of Medicine, The Chinese University of Hong Kong, Hong Kong

Email: janitachau@cuhk.edu.hk Tel: (852) 39436226 Fax: (852) 26035269 
Suzanne Hoi Shan LO, PhD, Assistant Professor, The Nethersole School of Nursing, Faculty of Medicine, The Chinese University of Hong Kong, Hong Kong

Email: suzannelo@cuhk.edu.hk Tel: (852) 39434485 Fax: (852) 26035269

Kam Ming CHAN, DN, Nurse Consultant (Neonatal Care), Kowloon East Cluster, Hospital Authority, Hong Kong

Email: chankm2@ha.org.hk Tel: (852) 39496419

Man Yi CHAN, MN, Nurse Consultant (Neonatal Care), Kowloon West Cluster, Hospital Authority, Hong Kong

Email: chanmy8@ha.org.hk Tel: (852)29901154

Vivian Wing Yan LEE, PhD, Associate Professor, Centre for Learning Enhancement And Research, The Chinese University of Hong Kong, Hong Kong Email: vivianlee@cuhk.edu.hk Tel: (852) 39438012 Fax: (852) 39420918

Simon Kwun Yu LAM, MN, Lecturer, The Nethersole School of Nursing, Faculty of Medicine, The Chinese University of Hong Kong, Hong Kong Email: simonlam@cuhk.edu.hk Tel: (852) 39439923 Fax: (852) 26035269

Kai Chow Choi, PhD, Senior Research Fellow, The Nethersole School of Nursing, Faculty of Medicine, The Chinese University of Hong Kong, Hong Kong

Email: kchoi@cuhk.edu.hk Tel: (852) 39434095 Fax: (852) 26035269 
David R Thompson, PhD, School of Nursing and Midwifery, Queen's University Belfast, Belfast, United Kingdom

Email: David.Thompson@qub.ac.uk Tel: (+44 289097 2865)～Fax: (+44 289097 2885)

\section{Funding Statement:}

This work was supported by the Teaching Development and Language Enhancement Grant for 2016-19 Triennium, University Grants Committee, Hong Kong (grant number: 4170479). The funding source had no involvement in the collection, analysis and interpretation of data, the writing of the report, and the decision to submit the article for publication.

\section{Conflict of Interest:}

None declared.

\section{Ethical Approval:}

The study was approved by the Survey and Behavioural Research Ethics Committee of The Chinese University of Hong Kong (Ref. No.: SBRE-18-038). Written informed consent was obtained from all participants prior to the study.

\section{Acknowledgements:}

The authors thank the nursing students for their involvement in the study.

Word Count: 5,133 (including abstract and references) 


\section{Abstract \\ Background}

Extravasation injury remains a significant preventable cause of morbidity and mortality in neonates. Equipping nursing students with the requisite knowledge and skills is essential for appropriate prevention, early detection, and management of extravasation injury.

\section{Objectives}

To develop a technology-enhanced, enquiry-based learning program for nursing students on the prevention and management of neonatal extravasation injury and examine its impact on their knowledge, approaches to studying and experience of learning.

\section{Design}

A pre-test/post-test study with qualitative evaluation.

\section{Settings}

Two university pre-registration nursing programs in Hong Kong.

\section{Participants}

A total of 192 senior-year nursing students.

\section{Methods}

A novel learning program was developed comprising 25 scenario-based video vignettes supplemented with critical-thinking exercises, discussion guides, interactive games, reading materials and a 3-hour in-class interactive workshop. Students received unlimited online access to the program. Data were collected at baseline and one-month post-workshop. Outcomes were students' level of knowledge of prevention and management of extravasation injuries and related care, approaches to studying, and experience of learning. Paired t-tests were performed on pre- post-test outcome data and individual semi-structured interviews were conducted at one-month post-workshop, transcribed verbatim and analyzed thematically.

\section{Results}


There were statistically significant improvements in students' level of knowledge and use of a deep approach to learning at one month compared with baseline. Students were highly satisfied with the program, appreciating the video vignettes and interactive small group discussions with academics and clinicians. Suggestions for enhancing the program included more time for the workshop, interaction with clinicians, and details on the administration of neonatal medications and dosages.

\section{Conclusions}

This study showed that a novel technology-enhanced, enquiry-based learning program was effective in enhancing nursing students' knowledge of the prevention and management of neonatal extravasation injury, approaches to studying and experience of learning.

(Word count: 287)

Keywords: Technology; Enquiry-based learning; Neonatal extravasation injury; Nursing students; Studying 


\section{Introduction}

Administration of intravenous therapy through peripheral intravenous or central venous access to provide fluids, medications, nutrition, or blood products is a critical component of care in neonatal intensive care units (NICUs) (Legemaat et al., 2016). Extravasation injury, which refers to the efflux of solutions from a vessel into surrounding tissue space, is a serious iatrogenic injury in newborns and infants receiving intravenous therapy (Corbett et al., 2019). Newborns and infants face a greater risk of developing peripheral extravasation injuries due to vein and skin fragility, with initial cannula misplacement or subsequent dislodgment increasing susceptibility to extravasation (Paquette et al., 2011). Studies report extravasation injuries in up to $70 \%$ of children receiving intravenous medications (Murphy et al., 2019) and in $92 \%$ of NICUs (Restieaux et al., 2013). A survey of a regional NICU in Hong Kong reported an injury incidence of 14 per 1,000 peripheral intravenous catheter days (Chan, 2017).

Extravasation injury remains a significant cause of morbidity and mortality in neonates (Kostogloudis et al., 2015). Irreversible sequelae of peripheral intravenous extravasation include skin ulcerations, necrosis, limb deformities, and disfigurement (Corbett et al., 2019; Goh et al., 2019). Umbilical venous catheter-related extravasation and central line extravasation are also associated with hepatic vascular thrombosis, venous thrombosis, peritoneal, retroperitoneal and pleural injuries, prolonged hospitalisation, increased medical costs, and even death (Chen et al., 2020; Goh et al., 2019; Restieaux et al., 2013). However, extravasation injury is preventable. Equipping nursing students with requisite knowledge and skills related to intravenous therapies in neonates is essential for the prevention, early detection, and management of extravasation injury.

Enquiry-based learning, a potential effective means of achieving this, refers to learning driven by a process of enquiry on real-life practice situations and emphasising student engagement (Theobald and Ramsbotham, 2019). Through this method, students are required to 
deeply engage with a problem, discuss solutions with peers, and critically analyse and reflect on associated underlying issues based on research evidence (Theobald and Ramsbotham, 2019). A substantial body of literature reported that adopting enquiry-based learning is conducive to creating a well-planned, versatile, and motivating learning environment for students. It helps provoke students' curiosity, develop their higher order thinking skills, and encourages interaction. It enhanced students' deeper understanding of the clinical situations and their satisfaction. These learning experiences may not be apparent in traditional didactic education (Nallen et al., 2018; Theobald and Ramsbotham, 2019).

In this information era, nursing students are used to search nursing or other healthrelated information via Internet or Apps applications using electronic mobile devices. These types of information technology is particularly useful for nursing students to enable real-time access to up-to-date information, and provide increased flexibility to teachers and learners for information retrieval and learning (Forbes et al., 2016). It is particularly useful for nursing students who are educated in a large class. It allows viewing and retrieval of useful information instantly while students are having clinical placement. Furthermore, use of information technology increases students' interest and motivation in learning by incorporating multimedia features including text, audios, still images, videos, animations, or games. These features are helpful in illustrating clearly the abstract concepts or complex clinical scenarios for better students' understanding (Forbes et al., 2016). Increasing studies reported that the adoption of technology-enhanced EBL in nursing education was associated with positive learning outcomes. It included better development of critical thinking skills and interests in learning among nursing students. This approach of learning with an e-learning component was acceptable by students with different learning styles (Rigby et al., 2012).

\section{Methods}

\subsection{Aims}


This study aimed to (1) develop a high-quality technology-enhanced, enquiry-based learning program for university pre-registration nursing students on the prevention and management of neonatal extravasation injury, and (2) examine its impact on students' knowledge, approaches to studying, and experience of learning.

\subsection{Design and setting}

A pre-test and post-test study with qualitative evaluation was conducted among students enrolled in two university pre-registration programs in Hong Kong.

\subsection{Participants}

All adult senior-year nursing students enrolled in pre-registration nursing programs in the 20192020 academic year were invited to participate in this study. We invited this group because they had received classes about caring for people with intravenous therapies but required further enhancement of knowledge and skills in managing intravenous therapy for neonates.

\subsection{Intervention}

We developed a technology-enhanced learning program guided by enquiry-based learning principles (Theobald and Ramsbotham, 2019). The program was produced by three nurse academics, three nurse consultants (pediatric and neonatal care), one department operations manager (pediatric care), and two advanced practice nurses (intensive care and medical care). Program learning resources included 25 scenarios covering essential aspects of the prevention and management of neonatal extravasation injuries including assessing neonates' conditions, securing an intravenous tubing, strategies to detect complications early, and administering medications. Each scenario consisted of a video-based vignette, critical-thinking exercises, discussion guides, interactive games, and further online readings. Critical-thinking exercises and discussion guides were related to identifying good or poor practice, anticipating possible complications, prioritizing nursing actions, and initiating therapeutic interventions. The total duration of all videotaped vignettes was 260 minutes. The critical-thinking exercises and 
discussion guides involved analysing good or poor nursing practice, anticipating possible complications, prioritising nursing actions, and justifying therapeutic interventions. All learning resources were installed in the university eLearning system, with unlimited online access given to students. Students also received a 3-hour in-class interactive workshop conducted by the research team to assimilate knowledge and skills through working on criticalthinking exercises and discussions with academics and clinicians.

\subsection{Data collection}

A pre-test was conducted before the intervention to determine students' baseline level of knowledge of extravasation injuries and related care, and their approach to learning. Students completed a self-administered paper-based questionnaire comprising a Knowledge Test (Chan, 2017) and a Revised Two Factor Study Process Questionnaire (R-SPQ-2F) (Biggs et al., 2001). They then received the intervention over the following two months. Three interactive workshops were conducted for all participating students (repeated sessions). A post-test was conducted at one-month post-workshop. Students completed the paper-based pre-test questionnaire again. Additionally, they completed a paper-based questionnaire that utilised a modified Experience of Learning Scale (Chau et al., 2007) at immediately post-workshop to indicate their satisfaction with the learning resources and workshop.

Individual, semi-structured face-to-face or phone 15-minute interviews in Cantonese were conducted at one-month post-workshop by two research team members. All four baccalaureate nursing students who participated in video production for the e-learning resources were interviewed about their perceptions of how the experience influenced their study, the area(s) that they enjoyed most, the knowledge and/or skills learned, and benefits gained. A convenience sub-sample of 20 students who received the intervention was interviewed about their experiences of using the learning resources and attending the workshop. They shared their views regarding the most and least helpful component(s) of the intervention, the knowledge 
and/or skills learned, the most interesting part(s), nurses' roles in preventing and managing neonatal extravasation injuries, and areas for enhancement.

\subsection{Outcomes measures}

\subsubsection{Students' knowledge}

A self-developed Knowledge Test in English (Chan, 2017), based on literature and evidencebased guidelines, was used to assess students' knowledge of extravasation injuries and related care. It consisted of 15 multiple-choice questions with four choices, covering risk factors (4 items), prevention (6 items), and management (5 items) of neonatal extravasation injuries. A score of one was given for each correct answer and zero for each incorrect answer. A total score was calculated by summing the score of all correct items (range, $0-15$ ). A higher score indicated better knowledge. The test was developed by a nurse consultant (neonatal care), and reviewed critically by an expert panel of a neonatologist, nurse consultant (neonatal care), ward manager and two advanced practice nurses in neonatal care (content validity: 0.95 ). Thirty nurses took the test and it showed acceptable reliability (Kuder-Richardson reliability coefficient: 0.761 ) (Chan, 2017).

\subsubsection{Students' approaches to studying}

A 20-item English version of the Revised Two Factor Study Process Questionnaire (R-SPQ2F) (Biggs et al., 2001) was used to evaluate students' approaches to studying. It consisted of four subscales in two main scales: Deep Approach (Deep Motive and Deep Strategy) and Surface Approach (Surface Motive and Surface Strategy). Deep approach refers to understanding and meaningful learning; surface approach refers to memorization and rote learning driven by a motivation to meet assessment requirements. Both approaches can be delineated into motives (reasons or goals to engage in learning behaviors), and strategies (methods, activities or processes engaged in during learning) (Entwistle and Ramsden, 2015). Each subscale contained five items rated on a 4-point Likert scale from 1 (never or only rarely 
true) to 4 (always or almost always true). Summing the score of the corresponding items yielded the subscale total score (range, 5-20). The total score of the main scale was calculated by summing the scores of its subscales (range, 10-40). A higher score indicated a higher preference of students to adopt that study approach. Cronbach's alpha of each subscale ranged from 0.62 to 0.72 (Biggs et al., 2001).

\subsubsection{Experience of learning}

An English version of a modified Experience of Learning Scale (Chau et al., 2007) was used to assess students' perception of usefulness of learning strategies adopted in the intervention, namely helpfulness to learn nursing skills and develop critical-thinking skills, relevance and appropriateness to learning needs and purposes, providing a clear purpose, and user-friendliness. It contained five items rated on a 5-point Likert scale from 1 (strongly disagree) to 5 (strongly agree).

\subsubsection{Demographic information}

Students' age, gender and year of study were collected.

\subsection{Ethical considerations}

The study was approved by the Survey and Behavioral Research Ethics Committee of The Chinese University of Hong Kong (Ref. No.: SBRE-18-038). It was conducted in adherence to local laws, the HK Personal Data (Privacy) Ordinance, the Declaration of Helsinki, institutional policies and the ICH-GCP. All students provided informed consent before commencement of data collection. All questionnaires were anonymous and kept strictly confidential for research purposes only.

\subsection{Data analyses}

Data are presented as frequency and percentage for categorical variables and as mean and standard deviation (SD) for continuous variables. Paired t-tests were performed to compare changes in outcomes between baseline and post-test. All analyses were performed using IBM 
SPSS Statistics Version 23 (IBM Corp., Armonk, NY). All statistical tests were two-sided with level of significance set at 0.05 . Interview data were transcribed verbatim from audio recordings by an independent research assistant and analyzed thematically. Sub-themes and themes meeting study objectives were developed.

\section{Results}

A total of 192 senior-year pre-registration nursing students (mean age $24.6 \pm 3.7$ ) participated in the study. Majority were female (73.4\%).

\subsection{Level of knowledge}

Fifty percent of students scored 8 or above out of 15 in the 15-item Knowledge Test (Chan, 2017) at baseline (Mean, $7.56 \pm 1.89$; Range, 1-12). There was a statistically significant increase in the mean total score to $11.05 \pm 2.51$ (Range, $1-15)$ at post-test $(p<0.001)$ (Table 1). Percentage of students who scored 8 or above increased to $76.7 \%$, with one student even scoring full mark. Compared with baseline, there were also statistically significant increases in all mean subscale scores, namely Risk factors, Prevention and Management of extravasation injuries, at post-test (all $p<0.001)$ (Table 1).

Regarding specific test items, seven items were answered correctly by over half of students (Range, 52.9-72.8\%) at baseline. Over 70\% of students correctly answered a Management item [M1] about immediate nursing actions for a neonate with grade 3 extravasation injury $(72.8 \%)$ and a Prevention item [P1] about signs and symptoms of central line extravasation (70.6\%).

At post-test, students performed the best in a Risk factor item [R1] about medications or solutions for administration via a central line (88.2\%). However, less than half of students answered a Prevention item [P2] about preventive measures for extravasation injuries $(39.6 \%)$ and a Risk factor item [R2] about identifying the neonate with the greatest risk for extravasation (23\%) correctly. Furthermore, R2 received the lowest percentage of correct answers at both pre-test $(18.5 \%)$ and post-test $(23 \%)$. 
The percentage of correct answers increased from baseline to post-test in 13 items (ranging from $4.5 \%$ to $51.3 \%$ ). A Prevention item [P3] about the frequency of assessing an intravenous site by nurses during administration of a high-risk medication or solution via a peripheral intravenous line showed the greatest improvement from 51.3\% to $74.8 \%$.

Two items showed a decrease in percentage of correct answers at post-test, namely a Prevention item [P2] about preventive measures for extravasation injuries (-13.3\%), and a Management item [M2] about nursing interventions for a neonate with central line extravasation causing pericardial effusion (-6.4\%). 39.6\% and 57.3\% of students answered P2 and M2 correctly at post-test, respectively.

\subsection{Approach to studying}

The mean scores of the main Deep approach scale and its two subscales of Deep motive and Deep strategy were relatively higher than the main Surface approach scale and its two subscales of Surface motive and Surface strategy at both pre-test and post-test (Table 2). Compared with baseline, there were statistically significant increases in the mean scores of Deep approach $(p=$ 0.002), Deep motive ( $p=0.002)$, and Deep strategy $(p=0.004)$ at post-test.

The mean scores of Surface approach, Surface motive and Surface strategy between baseline and post-test increased, but were not statistically significant (Surface approach, $p=$ 0.311; Surface motive, $p=0.489$; and Surface strategy, $p=0.155)$ (Table 2).

\subsection{Experience of learning}

Most (68.1-80.9\%) students strongly agreed or agreed that the learning materials were easy and good to use at home. They enjoyed and learnt much from them and would use them again immediately after the interventions, but least satisfied with their ease of use (Table 3).

\subsection{Interview data}

Three themes were generated from the interview data.

\subsubsection{Theme 1. Video vignettes helped guide enquiry-based critical-thinking}


All students who participated in the video production and the intervention highly appreciated the use of videos to simulate common clinical scenarios. Compared with traditional lectures or paper-based notes, viewing videos made it easier for students to understand how neonates with extravasation would behave in NICUs, and appraise nurses' responses to different changes in neonates' condition:

"I enjoyed viewing the video vignettes as they presented a 'very real' situation with a very 'live' newborn baby ... I definitely cannot imagine that by reading even scenarios on books or articles ... I can easily correlate how the intervention works for that situation presented ...”(Student A)

Some students added that they learnt a lot from critically examining the good and poor practices demonstrated by the nurses in the videos:

"The videos presented the scenarios, I see it as if I were working in real settings. It motivates me to dig out the problems... I would easily forget if it just 'described' the best practice." (Student B)

“We do not just 'identify', but 'analyze' why it is good or bad, this is very important ... there is no 'one way fits all' in clinical settings, we need to justify our interventions, I think these exercises are good to check our knowledge, alert us what signs (and symptoms) we need to be careful of, and show how to analyze clinical data gathered." (Student C)

Some students elaborated how the critical-thinking exercises, interactive games and discussion guides helped guide their inquiry into a problem. The list of further online readings supported their exploration of solutions:

"The multiple-choice questions and discussions in class stimulated me to think more, motivated me to find the correct answer. I think other lessons could follow a similar delivery format." (Student D) 


\subsubsection{Theme 2. Blending discussions with experts and self-directed learning}

All students enjoyed participating in the video production and workshop, especially the opportunity to work in small groups with academics and clinicians, usually neonatal nurse specialists:

"This experience was rewarding. I had close supervision with immediate feedback from some experts in the field when mastering the 'steps' to portray in the videos ... From this, I learned the most updated and practical knowledge and skills." (Student E)

A student remarked on the importance of the workshop as an opportunity to clarify difficult concepts and enhance their understanding through engaging with academics and clinicians:

"I can find ways to ask and solve my queries in the workshop, unlike when studying the e-learning materials, which is flexible but quite lonely ... and I doubt my understanding.” (Student F)

Students regarded the intervention as an innovative and effective way to learn advanced nursing skills and knowledge, and would strongly recommend it to other students to enhance their confidence in placements.

\subsubsection{Theme 3. More medication-related topics and longer workshop sessions}

Some students suggested additional topics for inclusion, particularly related to medication administration and calculations, and implications of nurses' assessment of early stage extravasation injuries in neonates and related management:

"I think it is very good that the session teaches us how to calculate the medications which is not covered in detail in usual lectures." (Student G)

Others suggested that they would like to have a longer workshop session with more sharing by nurse specialists about their clinical experiences: 
“The workshop is too short to explain all scenarios in detail. The clinicians' lived experience of care broadened my horizon ... inspired me to be more creative and critical in addressing patients' diversified health needs for improving the quality of care. I would appreciate it if we could have more of these sharing ..." (Student $\mathrm{H})$

\section{Discussion}

This study developed a novel technology-enhanced, enquiry-based learning program for preregistration nursing students and examined its impact on their knowledge of preventing and managing neonatal extravasation injury, approaches to studying and satisfaction with learning.

\subsection{Impact on knowledge}

Students performed poorly in the Knowledge Test at baseline. Although they learnt about the fundamental management of intravenous therapies and its complications earlier during their study, the results confirm their learning needs regarding the prevention and management of extravasation injuries in neonates. Given the advanced nursing knowledge and skills required (Odom et al., 2018), this study highlights the importance of providing this learning program to students in their senior year.

Students' knowledge of risk factors, prevention and management of neonatal extravasation injury improved significantly from baseline to post-test. Though there is a paucity of studies examining the effects of educational interventions on nursing students' knowledge of extravasation injury, there are consistent reports of the effects of enquiry-based learning on students' knowledge of other topics. For example, a pre-post-test study of 600 baccalaureate nursing students adopting work exemplars highlighting clinical reasoning and question prompts in learning resources about mental clinical skills and interactive discussions between students and teachers indicated improvements in knowledge (Theobald and Ramsbotham, 2019). A postintervention qualitative evaluation found enquiry-based learning of problems adapted from real scenarios enhanced baccalaureate senior-year nursing students' knowledge of guidelines and 
policies for resolving clinical dilemmas. Our findings lend support to this approach being effective in improving students' knowledge of advanced nursing concepts and skills (Theobald and Ramsbotham, 2019).

Students in our study performed poorly in three items related to recognizing high-risk neonates and identifying preventive or management measures for a given scenario, with a lower score in the latter two items a post-test. Risk factors for extravasation are multifaceted and related to patient, device, medication, and clinician (Desarno et al., 2018; Park et al., 2016). Assessing neonates who are unable to communicate clearly poses added challenges (Boyle et al., 2018). Students' poor performance might be attributed to their inadequate understanding of the differing risks, and specific preventive or management measures. Some studies report a significant increase in detection of extravasation in neonates and reduction in severe injuries in NICUs after offering tailored education for nurses. Essential topics include mechanisms of tissue damage related to medication classes, administration methods, neonates' characteristics, options for antidote administration, recognition of early-stage injuries, and when and how to take initial actions (Driscoll et al., 2015; Sangam, 2019). These topics could be strengthened in our intervention with more scenarios and explicit explanation, enhancing students' capabilities in performing a thorough assessment, synthesizing clinical information, and planning prompt prevention and management strategies for neonatal extravasation injury (Warren, 2011).

\subsection{Impact on approaches to studying}

We found that students tended to adopt a deep learning approach before exposure to the program, which was enhanced afterwards, highlighting the importance of critical learning activities examining underlying principles, mechanisms and rationale (Takase et al., 2019). Preregistration nursing education and professional practice require sound clinical reasoning skills and judgement for managing diverse health needs in a dynamic clinical environment (Carvalho et al., 2017; Lee et al., 2016). Of note is the insignificant increase in students' preference to 
use a surface learning approach post-intervention, possibly explained by their focus on imminent mid-term examinations and being more attuned to memorizing factual knowledge.

\subsection{Impact on experience of learning}

Students were highly satisfied with the program, particularly the videos simulating real clinical scenarios. Substantial evidence supports the use of such media in teaching nursing students' clinical knowledge and skills conveniently and flexibly (Coyne et al., 2018; Forbes et al., 2016). Moreover, students appreciated analyzing good and poor practices. Nurses' capabilities in exercising sound clinical reasoning and judgement are critically important in the current rapidly changing and demanding clinical environment (Lee et al., 2016), and adopting an enquiry-based learning approach emphasizing students' critical-thinking skills in entry-level nursing programs is increasingly favored (Carvalho et al., 2017).

Students valued the opportunity to learn from the lived experiences of academics and clinicians in small groups. This facilitates students' understanding of learning materials (Onda, 2012). Also, blending face-to-face groups with e-learning components appears to be the most effective form of learning for nursing students (Rigby et al., 2012). Students' reported least satisfaction with using the learning materials at home and suggested longer workshop sessions, expressing a preference for face-to-face discussions in addition to online learning resources.

Learning resources were posted on a platform with which students were familiar. Hence, the lowest score on ease of use of materials was unexpected. It may be due to students' perception that the content of the learning materials themselves was difficult, rather than the actual usability of the materials and platform. Nevertheless, the structure and content of the learning materials could be simplified with more guiding questions and guidance from teachers in the workshop (Abrami et al., 2011). Some students suggested more content on medication administration for neonates, which could be worthwhile given nurses' critical role in this regard for safe practice (Park et al., 2016). 


\title{
4.4. Limitations
}

This study has several limitations. First, we adopted a single group pre-test post-test design. The lack of a control group precluded a causal relationship between changes in outcomes and the program. Second, we measured changes in level of knowledge and students' approaches to studying in terms of a deep approach and surface approach at one-month post-intervention, which precluded examination of longer-term changes. Third, we did not measure the extent of students' use of the e-learning resources, so its association with outcomes cannot be determined.

\subsection{Implications}

Studies, ideally adopting an experimental design, to demonstrate a causal relationship between the program and outcomes are needed. Longer follow-up periods and process evaluation, and refinement and enhancement of the learning resources are recommended. Involving students, academics and clinicians in the production of e-learning resources and workshops to prevent and manage neonatal extravasation injury would seem a sensible multidisciplinary approach (Coyle et al., 2014).

\section{Conclusions}

This study showed that a novel technology-enhanced, enquiry-based learning program for preregistration nursing students is effective in enhancing their knowledge of neonatal extravasation injury, approaches to studying and experience of learning.

\author{
Abbreviations \\ NICU: Neonatal Intensive Care Unit; R-SPQ-2F: Revised Two Factor Study Process \\ Questionnaire
}

Submission declaration and verification 
No other manuscripts have been published previously, accepted, or submitted for publication using the same dataset. If accepted, this manuscript will not be published elsewhere in the same form, in English or in any other language, or electronically, without the written consent of the copyright-holder. All authors have seen this manuscript and agreed to the authorship order and content.

\section{Consent for publication}

Not applicable.

\section{Data statement}

The datasets generated and analyzed during the current study are available from the corresponding author on reasonable request.

\section{References}

Abrami, P., Bernard, C., Bures, R., Borokhovski, M., Tamim, E., 2011. Interaction in distance education and online learning: using evidence and theory to improve practice. Journal of Computing in Higher Education 23(2), 82-103. https://doi.org/10.1007/s12528-0119043-x.

Biggs, J., Kember, D., Leung, D. Y., 2001. The revised two-factor Study Process Questionnaire: R-SPQ-2F. British Journal of Educational Psychology 71(1), 133-149. https://doi.org/10.1348/000709901158433.

Boyle, E. M., Bradshaw, J., Blake, K. I., 2018. Persistent pain in neonates: challenges in assessment without the aid of a clinical tool. Acta Paediatrica 107(1), 63-67. https://doi.org/10.1111/apa.14081. 
Carvalho, D., Azevedo, I. C., Cruz, G., Mafra, G., Rego, A., Vitor, A. F., Santos, V., Cogo, A., Ferreira J A., , M. A., 2017. Strategies used for the promotion of critical thinking in nursing undergraduate education: a systematic review. Nurse Education Today 57, $103-$ 107. https://doi.org/10.1016/j.nedt.2017.07.010.

Chan, K. M., 2017. Development implementation and evaluation of a clinical practice guideline on prevention and management of neonatal extravasation injuries (Order No. 10757543). Available from Dissertations \& Theses @ Chinese University of Hong Kong, ProQuest Dissertations \& Theses A\&I. (2010993502). Retrieved from http://easyaccess.lib.cuhk.edu.hk/login?url=https://search.proquest.com/docview/2010 993502? accountid=10371

Chau, J., Lee, T., Hazalett, C., 2007. Report of an impact study on 'Incorporating assessments as a complementary means to direct desired learning in nursing'. University Grants Committee Teaching Development Grant, Hong Kong.

Chen, H. J., Chao, H. C., Chiang, M. C., Chu, S. M., 2020. Hepatic extravasation complicated by umbilical venous catheterization in neonates: a 5-year, single-center experience. Pediatrics and Neonatology 61(1), 16-24. https://doi.org/10.1016/j.pedneo.2019.05.004.

Corbett, M., Marshall, D., Harden, M., Oddie, S., Phillips, R., McGuire, W., 2019. Treating extravasation injuries in infants and young children: a scoping review and survey of UK NHS practice. BMC Pediatrics 19(1), 6. https://doi.org/10.1186/s12887-018-1387-1.

Coyle, C. E., Griffie, J., Czaplewski, L. M., 2014. Eliminating extravasation events: a multidisciplinary approach. Journal of Infusion Nursing 37(3), 157-164. https://doi.org/10.1097/NAN.0000000000000034.

Coyne, E., Rands, H., Frommolt, V., Kain, V., Plugge, M., Mitchell, M., 2018. Investigation of blended learning video resources to teach health students clinical skills: an integrative 
review. Nurse Education Today $\quad$ 63, 101-107. https://doi.org/10.1016/j.nedt.2018.01.021.

Desarno, J., Sandate, I., Green, K., Chavez, P., 2018. When in doubt, pull the catheter out: implementation of an evidence-based protocol in the prevention and management of peripheral intravenous infiltration/extravasation in neonates. Neonatal Network 37(6), 372-377. https://doi.org/10.1891/0730-0832.37.6.372.

Driscoll, C., Langer, M., Burke, S., El Metwally, D., 2015. Improving detection of IV infiltrates in neonates. BMJ Quality Improvement Reports 4(1), u204253.w3874. https://doi.org/10.1136/bmjquality.u204253.w3874.

Entwistle, N., Ramsden, P., 2015. Understanding student learning. Routledge, New York, NY.

Forbes, H., Oprescu, F. I., Downer, T., Phillips, N. M., McTier, L., Lord, B., Barr, N., Alla, K., Bright, P., Dayton, J., Simbag, V., Visser, I., 2016. Use of videos to support teaching and learning of clinical skills in nursing education: a review. Nurse Education Today 42, 53-56. https://doi.org/10.1016/j.nedt.2016.04.010.

Goh, S., Kan, S. Y., Bharadwaj, S., Poon, W. B., 2019. A review of umbilical venous catheterrelated complications at a tertiary neonatal unit in Singapore. Singapore Medical Journal 10.11622/smedj.2019140. https: /doi.org/10.11622/smedj.2019140.

Kostogloudis, N., Demiri, E., Tsimponis, A., Dionyssiou, D., Ioannidis, S., Chatziioannidis, I., Nikolaidis, N., 2015. Severe extravasation injuries in neonates: a report of 34 cases. Pediatric Dermatology 32(6), 830-835. https://doi.org/10.1111/pde.12664.

Lee, J., Lee, Y. J., Bae, J., Seo, M., 2016. Registered nurses' clinical reasoning skills and reasoning process: a think-aloud study. Nurse Education Today 46, 75-80. https://doi.org/10.1016/j.nedt.2016.08.017.

Legemaat, M., Carr, P. J., van Rens, R. M., van Dijk, M., Poslawsky, I. E., van den Hoogen, A., 2016. Peripheral intravenous cannulation: complication rates in the neonatal 
population: a multicenter observational study. Journal of Vascular Access 17(4), 360365. https://doi.org/10.5301/jva.5000558.

Murphy, A. D., Gilmour, R. F., Coombs, C. J., 2019. Extravasation injury in a paediatric population. ANZ Journal of Surgery 89(4), E122-E126. https://doi.org/10.1111/ans.14104.

Nallen, K., Spence, D., Porter, S., 2018. Does Enquiry Based Learning (EBL) impact on clinical practice? a qualitative exploration of midwifery graduates' perceptions. Midwifery 63(2018), 17-19. https://doi.org/10.1016/j.midw.2018.04.018.

Odom, B., Lowe, L., Yates, C., 2018. Peripheral infiltration and extravasation injury methodology: a retrospective study. Journal of Infusion Nursing 41(4), 247-252. https://doi.org/10.1097/NAN.0000000000000287.

Onda, E., 2012. Situated cognition: its relationship to simulation in nursing education. Clinical Simulation in Nursing 8(7), E273-E280. https://doi.org/10.1016/j.ecns.2010.11.004.

Paquette, V., McGloin, R., Northway, T., Dezorzi, P., Singh, A., Carr, R., 2011. Describing Intravenous Extravasation in Children (DIVE Study). Canadian Journal of Hospital Pharmacy 64(5), 340-345. https://doi.org/10.4212/cjhp.v64i5.1069.

Park, S. M., Jeong, I. S., Jun, S. S., 2016. Identification of risk factors for intravenous infiltration among hospitalized children: a retrospective study. PLoS ONE 11(6), e0158045. https://doi.org/10.1371/journal.pone.0158045.

Restieaux, M., Maw, A., Broadbent, R., Jackson, P., Barker, D., Wheeler, B., 2013. Neonatal extravasation injury: prevention and management in Australia and New Zealand-a survey of current practice. BMC Pediatrics 13, 34. https://doi.org/10.1186/1471-2431$13-34$.

Rigby, L., Wilson, I., Baker, J., Walton, T., Price, O., Dunne, K., Keeley, P., 2012. The development and evaluation of a 'blended' enquiry based learning model for mental 
health nursing students: "making your experience count". Nurse Education Today 32(3), 303-308. https://doi.org/10.1016/j.nedt.2011.02.009.

Sangam, S. L., 2019. Quality improvement measures for early detection of severe intravenous infiltration in infants. BMJ Open Quality 8(2), e000407. https://doi.org/10.1136/bmjoq2018-000407.

Takase, M., Imai, T., Niitani, M., Okada, M., 2019. Teaching context contributing to nursing students' adoption of a deep approach to learning. Journal of Professional Nursing 35(5), 379-388. https://doi.org/10.1016/j.profnurs.2019.04.006.

Theobald, K. A., Ramsbotham, J., 2019. Inquiry-based learning and clinical reasoning scaffolds: an action research project to support undergraduate students' learning to 'think like a nurse'. Nurse Education in Practice 38, 59-65. https://doi.org/10.1016/j.nepr.2019.05.018.

Warren, D., 2011. Implementation of a protocol for the prevention and management of extravasation injuries in the neonatal intensive care patient. International Journal of Evidence-based Healthcare 9(2), 165-171. https://doi.org/10.1111/j.17441609.2011.00213.x. 